\title{
Particle Size Affects Concentration-Dependent Cytotoxicity of Chitosan Nanoparticles towards Mouse Hematopoietic Stem Cells
}

\author{
Siti Sarah Omar Zaki, Mohd Nazmi Ibrahim, and Haliza Katas \\ Drug Delivery and Novel Targeting Research Group, Centre for Drug Delivery Research, Faculty of Pharmacy, \\ Universiti Kebangsaan Malaysia, Jalan Raja Muda Abdul Aziz, 50300 Kuala Lumpur, Malaysia
}

Correspondence should be addressed to Haliza Katas; haliz12@hotmail.com

Received 6 February 2015; Accepted 5 April 2015

Academic Editor: Paresh Chandra Ray

Copyright (C) 2015 Siti Sarah Omar Zaki et al. This is an open access article distributed under the Creative Commons Attribution License, which permits unrestricted use, distribution, and reproduction in any medium, provided the original work is properly cited.

Chitosan nanoparticles (CSNPs) have been extensively applied in medical and pharmaceutical fields as promising drug delivery systems. Despite that, the safety of CSNPs remains inadequate and needs further investigation, particularly on hematopoietic stem cells (HSCs). CSNPs were prepared by ionic gelation method and later were characterized for their physical characteristics (particle size and zeta potential). Cytotoxicity of CSNPs was assessed by MTT assay. Particle size was highly influenced by chitosan concentration and molecular weight (medium and high molecular weight (MMW and HMW)). Higher chitosan concentration and molecular weight produced larger nanoparticles. Zeta potential of CSNPs was not significantly affected by chitosan concentrations and molecular weights used in the present study. MMW had a better stability than HMW CSNPs as their particle size and zeta potential were not significantly altered after autoclaving. Cytotoxicity of CSNPs was influenced by zeta potential and particle size. On the other hand, chitosan concentration and molecular weight indirectly influenced cytotoxicity by affecting particle size and zeta potential of CSNPs. In conclusion, cytotoxicity of CSNPs was mainly attributed to their physical characteristics and this opens a strategy to ensure the safety of CSNPs applications in stem cell technology.

\section{Introduction}

Chitosan is a cationic polysaccharide derived from natural sources including shell of crabs and shrimps [1] and microorganisms like fungus [2]. Chitosans have been widely used as carriers for drugs and genetic materials, including DNA [3]. Chitosan has also been widely applied in pharmaceutical field due to its biodegradability and biocompatibility properties [4]. Additionally, chitosan is able to effectively cross the epithelium and, therefore, acts as permeability enhancer [1].

Nanoparticles are small solid colloidal particles with diameters ranging from 1 to $1000 \mathrm{~nm}$. Ionic gelation method was commonly used to prepare chitosan (CSNPs) due to its simplicity [4]. Besides the solubility of chitosan in aqueous media, heating, organic solvent, and high shear force are not required for this method [5], making it a suitable method to produce nontoxic nanoparticles. However, cytotoxicity effects of CSNPs could be affected by several other factors such as their physical characteristics which could be influenced by various parameters, for example, chitosan concentration, molecular weight, and degree of deacetylation (DD) $[4,6,7]$.

Many studies on cytotoxicity of CSNPs have been previously reported on cultured cells, for example, A549 human alveolar epithelial cells [3], while others have been tested on zebra fish model [8]. Other studies [9] reported the antitumor effect of paclitaxel-bound nanoparticles in gastric cancer cells, with majority of cell populations in the early and late apoptosis stages. However, cytotoxicity of CSNPs on stem cells has not been previously investigated although CSNPs have been extensively applied in stem cells technology. CSNPs have been investigated to load and deliver hepatocytes growth factor for liver transplantation in chronic cirrhosis patient [10]. Based on the study, CSNPs were able to facilitate stem cells differentiation process. However, toxic effect of 
these nanoparticles on stem cells was not determined and, therefore, it needs to be described further.

The present study was carried out to evaluate the effects of molecular weight and concentration of chitosan on the physical characteristic as well as cytotoxicity of CSNPs on HSCs. Relationships between physical characteristics of CSNPs and cytotoxicity effects were also evaluated in this study. Furthermore, the effect of autoclave (to sterilize CSNPs) on the stability of CSNPs was also assessed to ensure the safety of CSNPs in future applications.

\section{Materials and Methods}

2.1. Materials. Chitosan of medium molecular weight (MMW) and high molecular weight (HMW) (Sigma-Aldrich, St. Louis, USA), pentasodium tripolyphosphate (TPP) (Darmstadt, Germany), acetic acid $(2 \% \mathrm{w} / \mathrm{v})$, phosphate buffered saline (PBS, pH 7.4-7.5), 3-(4,5-dimethylthiazol2yl)-2,5-diphenyltetrazolium bromide (MTT powder) (Sigma, USA), Dulbecco's Modified Eagle's Medium (DMEM) (GIBCO), dimethyl sulfoxide (DMSO), and trypan blue were used as received. HSCs were obtained from male mice (ICR strain, average weight $28-32 \mathrm{~g} / \mathrm{kg}$ ). The cells were cultured in DMEM supplemented with $10 \%$ fetal bovine serum (FBS), 2\% Pen-Strep (100 $\mu \mathrm{g} / \mathrm{mL}$ Penicillin, $100 \mu \mathrm{g} / \mathrm{mL}$ Streptomycin), $100 \mathrm{ng} / \mathrm{mL}$ stem cell factor (SCF), $5 \mathrm{ng} / \mathrm{mL}$ interleukin-3 (IL-3), and $10 \mathrm{ng} / \mathrm{mL}$ interleukin-6 (IL-6) for $24 \mathrm{~h}$ at $37^{\circ} \mathrm{C}, 5 \% \mathrm{CO}_{2}$.

2.2. Preparation and Characterization of CSNPs. CSNPs were prepared by ionic gelation method [11] with some modification. Firstly, chitosan solution was prepared by dissolving chitosan powder of MMW (0.02-0.06 g) and HMW (0.02$0.03 \mathrm{~g})$ in $0.2 \mathrm{~mL}(2 \% \mathrm{w} / \mathrm{v})$ acetic acid. Later, distilled water was added to a total volume of $10 \mathrm{~mL}$. The concentration of chitosan solution prepared was $0.2 \%$ and $0.3 \% \mathrm{w} / \mathrm{v}$ for HMW, while from $0.2 \%$ to $0.6 \% \mathrm{w} / \mathrm{v}$ for MMW. CSNPs were spontaneously produced when $1.2 \mathrm{~mL}$ TPP $(0.1 \% \mathrm{w} / \mathrm{v})$ was added into $3 \mathrm{~mL}$ of chitosan solution under a constant magnetic stirring at $700 \mathrm{rpm}$ for $30 \mathrm{~min}$ at room temperature. The nanoparticles were then left at room temperature for another $30 \mathrm{~min}$. CSNPs were collected by ultracentrifugation at $28,000 \mathrm{rpm}$, at $25^{\circ} \mathrm{C}$ for $30 \mathrm{~min}$ (Optima L-100 XP, Beckman-Coulter, California, USA). The supernatants recovered from centrifugation were discarded and the pellets were resuspended in distilled water. After that, the particles were vortexed to form homogenous CSNPs suspensions. Nanoparticles were measured for their particle size and zeta potential (surface charge) using Zetasizer ZS-90 (Malvern Instruments, Worcestershire, UK). Particle size analysis was done at $90^{\circ} \mathrm{C}$ and at $25^{\circ} \mathrm{C}$.

2.3. Determination of CSNPs Stability. Physical stability of CSNPs was evaluated based on changes in particle size and zeta potential after autoclaving process. CSNPs were autoclaved at $121^{\circ} \mathrm{C}$ for $20 \mathrm{~min}$ for sterilization purpose prior to cytotoxicity assay. Particle size and zeta potential of sterilized CSNPs were measured using Zetasizer ZS-90 (Malvern
Instruments, Worcestershire, UK) and were compared with the measurement done before autoclaving process.

2.4. Cell Culture. MBMCs were isolated from ICR strain mouse origin using the standard "flushing" technique [12]. Mice were sacrificed by cervical dislocation method as approved by the Universiti Kebangsaan Malaysia Animal Ethics Committee (UKMAEC) with the approval number FF/2012/HALIZA/21-NOV./476-NOV.-2012-JAN.-2014-AR-

CAT2. Bones (femurae and tibiae) were flushed with $2 \%$ DMEM and single-cell suspensions of the cells were made using $40 \mu \mathrm{m}$ cell strainer. MBMCs were then centrifuged at 2,500 rpm for $7 \mathrm{~min}$ and the collected cells (pellets) were resuspended in $10 \mathrm{~mL}$ of growth medium (DMEM supplemented with 10\% FBS, 2\% Pen-Strep (100 U/mL Penicillin, $100 \mu \mathrm{g} / \mathrm{mL}$ Streptomycin), $100 \mathrm{ng} / \mathrm{mL}$ stem cell factor (SCF), $5 \mathrm{ng} / \mathrm{mL}$ interleukin-3 (IL-3), and $10 \mathrm{ng} / \mathrm{mL}$ interleukin-6 (IL-6)). The isolated MBMCs were then cultured in $75 \mathrm{~cm}^{2}$ cell culture flask and grown at a density of $1 \times 10^{6}$ cells $/ \mathrm{mL}$ of growth medium at $37^{\circ} \mathrm{C}$ in $5 \% \mathrm{CO}_{2}$ incubator for $24 \mathrm{~h}$ duration.

2.5. In Vitro Cytotoxicity Assay. In this study, cytotoxicity of chitosan solution and nanoparticles on mouse HSCs was evaluated using MTT assay [13]. Sterile CSNPs (autoclaved) were used in this assay and three concentrations of CSNPs were prepared $(10,100$, and $1000 \mu \mathrm{g} / \mathrm{mL})$. HSCs were obtained from mouse bone marrow, cultured and incubated for $24 \mathrm{~h}$ at $37^{\circ} \mathrm{C}$ and $5 \% \mathrm{CO}_{2}$. After $24 \mathrm{~h}$ of incubation, HSCs suspension was prepared in a concentration of $2 \times 10^{6}$ cells $/ \mathrm{mL}$ in DMEM. $100 \mu \mathrm{L}$ of HSCs suspension was seeded into each well of 96-well plates. Later, $100 \mu \mathrm{L}$ of CSNPs was added into the wells. Afterwards, the plates were incubated at $37^{\circ} \mathrm{C}, 5 \%$ $\mathrm{CO}_{2}$ for another $24 \mathrm{~h}$. In $24 \mathrm{~h}$ of incubation, $20 \mu \mathrm{L}$ of MTT solution $(5 \mathrm{mg} / \mathrm{mL})$ was added into each well and incubated for another $4 \mathrm{~h}$ at $37^{\circ} \mathrm{C}$ and $5 \% \mathrm{CO}_{2}$. Afterwards, supernatant in the sample and control (cells exposed to DMEM only) wells was decanted and replaced with $150 \mu \mathrm{L}$ of DMSO followed by $15 \mathrm{~min}$ of incubation. The plates were then analyzed by using a microplate reader (Model HO2431 Expert Plus) and measured at a wavelength of $570 \mathrm{~nm}$. Cell viability was expressed as percentage of absorbance of sample to control [3].

\section{Results}

\subsection{Particle Size and Zeta Potential}

3.1.1. Effects of Chitosan Concentration and Molecular Weight. Table 1 shows the effects of different chitosan concentrations on particle size and zeta potential of CSNPs prepared from MMW and HMW chitosans. For MMW, particle size was increased with increasing chitosan concentration from $0.2 \%$ to $0.6 \% \mathrm{w} / \mathrm{v}$. However, zeta potential of these CSNPs was not significantly affected by chitosan concentration. Particle size of HMW CSNPs was also significantly increased from $987.3 \pm$ $54.1 \mathrm{~nm}$ to $1651.2 \pm 118.0 \mathrm{~nm}$ when chitosan concentration was increased from $0.2 \%$ to $0.3 \% \mathrm{w} / \mathrm{v}$. Similar to MMW, chitosan concentration did not affect zeta potential of HMW 
TABLE 1: Effects of autoclaving process and chitosan concentrations on particle size and zeta potential of CSNPs prepared from MMW chitosan, $n=3$.

\begin{tabular}{lcccr}
\hline \multirow{2}{*}{$\begin{array}{l}\text { Chitosan } \\
\text { concentrations (w/v) }\end{array}$} & \multicolumn{2}{c}{ Before autoclaving } & \multicolumn{2}{c}{ After autoclaving } \\
& Particle size $(\mathrm{nm} \pm \mathrm{SD})$ & Zeta potential $(\mathrm{mV} \pm \mathrm{SD})$ & Particle size $(\mathrm{nm} \pm \mathrm{SD})$ & Zeta potential $(\mathrm{mV} \pm \mathrm{SD})$ \\
\hline 0.2 & $490.7 \pm 99.2$ & $+54.3 \pm 0.3$ & $712.1 \pm 56.8$ & $+55.9 \pm 3.7$ \\
0.3 & $826.3 \pm 75.9$ & $+56.6 \pm 1.4$ & $1363.3 \pm 95.6$ & $+62.0 \pm 1.9$ \\
0.4 & $1413.7 \pm 12.3$ & $+64.5 \pm 0.5$ & $1406.7 \pm 75.0$ & $+61.5 \pm 2.7$ \\
0.5 & $1979.5 \pm 89.5$ & $+63.7 \pm 2.3$ & $1556.3 \pm 146.9$ & $+62.3 \pm 2.9$ \\
0.6 & $2195.7 \pm 40.4$ & $+66.7 \pm 5.5$ & $1756.3 \pm 47.1$ & $+60.1 \pm 4.0$ \\
\hline
\end{tabular}

TABLE 2: Effects of autoclaving process and chitosan concentrations on particle size and zeta potential of CSNPs prepared from HMW of chitosan, $n=3$.

\begin{tabular}{lcccc}
\hline \multirow{2}{*}{$\begin{array}{l}\text { Chitosan } \\
\text { concentrations }(\% \mathrm{w} / \mathrm{v})\end{array}$} & Particle size $(\mathrm{nm} \pm \mathrm{SD})$ & Zeta potential $(\mathrm{mV} \pm \mathrm{SD})$ & Particle size $(\mathrm{nm} \pm \mathrm{SD})$ & Zeta potential $(\mathrm{mV} \pm \mathrm{SD})$ \\
\hline 0.2 & $987.3 \pm 54.1$ & $+63.4 \pm 2.9$ & $2164.3 \pm 107.8$ & $+69.0 \pm 1.9$ \\
0.3 & $1651.2 \pm 118.0$ & $+63.9 \pm 4.1$ & $3660.0 \pm 96.3$ & $+71.5 \pm 10.1$ \\
\hline
\end{tabular}

CSNPs. In contrast to that, particle size of CSNPs was influenced by molecular weight of chitosan. Larger size and higher surface charge of particles were obtained when HMW chitosan was used.

3.1.2. Effects of Autoclave. The particle size of MMW CSNPs was increased from $490.7 \pm 99.24 \mathrm{~nm}$ to $712.1 \pm 56.8 \mathrm{~nm}$ and from $826.3 \pm 75.9 \mathrm{~nm}$ to $1363.3 \pm 95.6 \mathrm{~nm}$ for $0.2 \%$ and $0.3 \% \mathrm{w} / \mathrm{v}$ chitosans, respectively, after autoclaving process. In contrast, the particle size of MMW CSNPs prepared from chitosan concentrations of $0.4 \%, 0.5 \%$, and $0.6 \% \mathrm{w} / \mathrm{v}$ was decreased as shown in Table 1. Similar trends were observed for zeta potential of MMW CSNPs. Although particle size and zeta potential were slightly altered after autoclaving process, the changes were not statistically significant, suggesting these CSNPs were physically stable. On the other hand, the particle size of CSNPs prepared from HMW chitosan was significantly increased from $987.3 \pm 54.1 \mathrm{~nm}$ to $2164.3 \pm$ $107.8 \mathrm{~nm}$ and from $1651.2 \pm 118.0 \mathrm{~nm}$ to $3660.0 \pm 96.3 \mathrm{~nm}$ for chitosan concentrations of $0.2 \%$ and $0.3 \% \mathrm{w} / \mathrm{v}$, respectively. This indicated instability of the system which might be attributed to formation of aggregates (Table 2). Conversely, zeta potential of HMW CSNPs was not significantly affected by autoclaving process.

\subsection{Cytotoxicity Effects of CSNPs on HSCs}

3.2.1. Effect of Chitosan Concentration. Cytotoxicity effects of MMW and HMW CSNPs prepared from various chitosan concentrations on cell viability are shown in Figures 1 and 2, respectively. At the highest CSNPs concentration $(1000 \mu \mathrm{g} / \mathrm{mL})$, the smallest particle size produced from $0.2 \%$ $\mathrm{w} / \mathrm{v}$ chitosan had shown the lowest cell viability $(74.42 \% \pm$ 9.11). Meanwhile, significant increase in cell viability $(117.13 \%$ \pm 12.40 ) was noted for CSNPs prepared from $0.4 \% \mathrm{w} / \mathrm{v}$ chitosan at the lowest concentration of CSNPs $(10 \mu \mathrm{g} / \mathrm{mL})$.

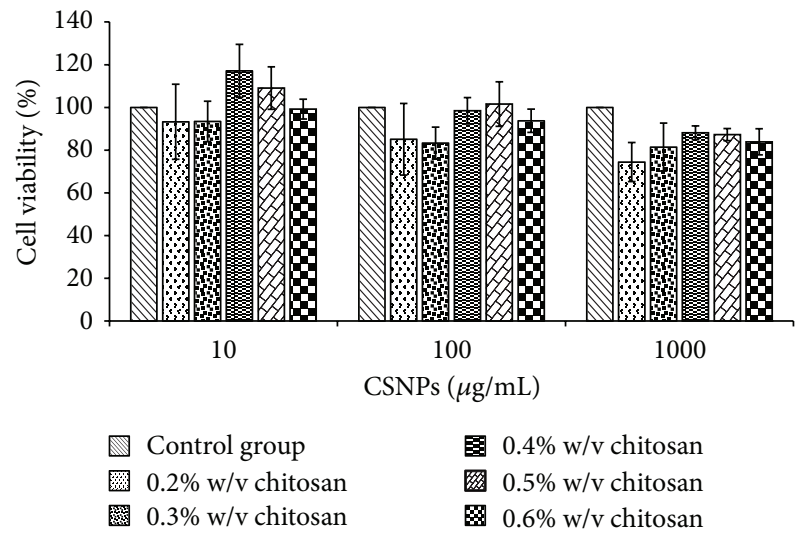

FIGURE 1: Effects of MMW CSNPs on cell viability of HSCs, $n=3$.

Similar findings were observed for HMW CSNPs. At the highest CSNPs concentration, smaller particle size had lower cell viability $(76.63 \% \pm 2.31)$. Despite that, CSNPs were relatively nontoxic regardless of particle size at low CSNPs concentrations (10 and $100 \mu \mathrm{g} / \mathrm{mL}$ ). As similar cytotoxicity effect was observed for both MMW and HMW CSNPs, chitosan molecular weight was expected to play lesser role in influencing cell viability of HSCs at the selected CSNPs concentrations. In comparison with chitosan solution, cell viability of HSCs exposed to CSNPs was not significantly different (data is not shown).

\section{Discussion}

CSNPs were prepared by ionic gelation method because it offers a simple and mild preparation procedure in aqueous environment [4]. Besides, the method has been proven to produce nontoxic nanoparticles and act as good drug carriers [4]. CSNPs are formed spontaneously after the addition 

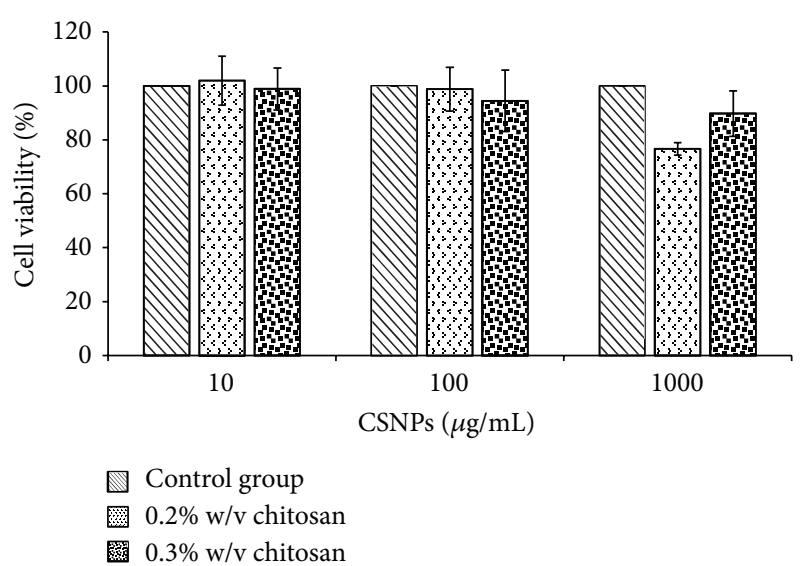

FIgURE 2: Effects of HMW CSNPs on cell viability of HSCs, $n=3$.

of tripolyphosphate (TPP) into chitosan solution. TPP is considered as a safer agent compared to other chemical cross linkers such as glutaraldehyde which have higher possibility to exert toxic effects [14].

In the case of HMW chitosan, nanoparticles could not be produced at concentration of more than $0.3 \% \mathrm{w} / \mathrm{v}$. A previous study [11] reported that the formation of CSNPs was only possible for some specific chitosan concentrations and microparticles formation could be avoided if the concentration is below $0.3 \% \mathrm{w} / \mathrm{v}$.

Based on the results obtained, particle size of CSNPs increased as the chitosan concentration was increased for both molecular weights. Smaller particle size was produced with lower chitosan concentration and vice versa. The small particle size obtained was partly due to decreased viscosity of chitosan solution which had a better solubility for more efficient gelation process. The same finding was reported by others $[4,15,16]$. Large particle size was obtained for all concentrations except for $0.2 \% \mathrm{w} / \mathrm{v}$ chitosan. Larger particle size is commonly produced when MMW and HMW chitosans are used at a concentration higher than the limiting concentration. In case of chitosan concentration being more than the limiting concentration $(0.25 \%$ and $0.15 \% \mathrm{w} / \mathrm{v}$ for MMW and HMW, resp.), the particles will start to aggregate and form large particles [16]. Other than concentration, molecular weight of chitosan may also affect the size of nanoparticles. HMW chitosan has a lower aqueous solubility and therefore tends to form larger particles compared to MMW. MMW chitosan is more efficient to interact with TPP compared to HMW. Low solubility of HMW chitosan promotes aggregation upon interaction with TPP and results in increased mean particle diameter of nanoparticles as revealed by others $[4,14,16]$. Therefore, particle size could be reduced by using lower molecular weight chitosan as it has shorter polymer chains that favor dissolution and interaction with TPP [3].

On the contrary, chitosan concentration did not cause significant alteration in zeta potential of both molecular weights. Although HMW chitosan produced nanoparticles with slightly higher zeta potential values than MMW chitosan, the difference was not statistically significant. This finding was in accordance with a previous study [3] which reported that molecular weight had minimal effect on the zeta potential of CSNPs. A possible reason for this is the difference in molecular weight for the polymer chain which also explains the tendency of molecular weight to affect particle size more than zeta potential of nanoparticles [4].

MMW CSNPs were considered stable based on the results of their particle size while HMW CSNPs showed a sign of physical instability at high temperature and pressure (increased particle size). Additionally, zeta potential of CSNPs of both molecular weights was not significantly altered after autoclaving process which suggested that the process affected the physical stability more than chemical stability as their $\mathrm{pH}$ values remained unchanged after autoclaving (data are not shown).

Cytotoxic effects of CSNPs on HSCs for both MMW and HMW chitosans were not directly influenced by chitosan concentration and molecular weight. Instead, they were affected by particle size of CSNPs as the smaller size was more cytotoxic compared to larger ones. However, other factors may also contribute to cytotoxicity effect of CSNPs. For example, DD has been reported to affect cytotoxicity more than the molecular weight [3]. This is mainly because DD has a major impact on surface charge of CSNPs. The results obtained in this study were in good agreement with other studies; thereby, molecular weight of chitosan could be considered as a less important contributing factor to cytotoxicity effect $[17,18]$. Interestingly, cytotoxicity is also related to the overall charge density of the particles (commonly attributed by higher nanoparticles concentration/dose exposed to the cells) as its increment causes higher toxicity of nanoparticles [19]. In light of this, it can be suggested that molecular weight of chitosan has indirect effect on the viability of HSCs. In this study, particle size was observed to influence HSCs viability more. This could be the result of similar values of zeta potential exhibited by CSNPs prepared from various concentrations. Nevertheless, the influence of zeta potential could still be seen especially at a very high concentration of CSNPs $(100 \mu \mathrm{g} / \mathrm{mL})$, in which higher loss of cells was noted especially for the smallest particle size as more nanoparticles contributed to higher overall positive charge density.

These findings therefore revealed that CSNPs with high zeta potential values would not always be cytotoxic towards cells. The size and concentration of particles play more important role to determine the toxic effect of nanoparticles $[3,8]$. The findings obtained also suggested that chitosan is nontoxic even though it was transformed into nanoparticles.

\section{Conclusions}

Cytotoxicity effects of CSNPs have been shown to be relatively low, concentration-dependent, and influenced by particle size of CSNPs. In addition, stability of MMW CSNPs was maintained after autoclaving process, whereas HMW CSNPs was prone to form aggregates, suggesting autoclaving is not always the best method to sterilize CSNPs. Moreover, particle size of CSNPs was considered as the main contributing factor for cytotoxicity effect of CSNPs towards HSCs, which had 
been indirectly influenced by chitosan concentration and molecular weight.

\section{Conflict of Interests}

The authors declare that there is no conflict of interests regarding the publication of this paper.

\section{Acknowledgments}

The authors gratefully acknowledge the Ministry of Education, Malaysia. The project was supported by funds from FRGS/1/2012/SKK02/UKM/02/1 and Universiti Kebangsaan Malaysia.

\section{References}

[1] M. S. Kumar, P. S. Kumar, M. Alok, R. Neha, and S. Raghvendra, "Chitosan: a novel excipient in pharmaceutical formulation," Institute of Pharmacy, vol. 2, pp. 2266-2277, 2011.

[2] L. Illum, "Chitosan and its use as a pharmaceutical excipient," Pharmaceutical Research, vol. 15, no. 9, pp. 1326-1331, 1998.

[3] M. Huang, E. Khor, and L.-Y. Lim, "Uptake and cytotoxicity of chitosan molecules and nanoparticles: effects of molecular weight and degree of deacetylation," Pharmaceutical Research, vol. 21, no. 2, pp. 344-353, 2004.

[4] Z.-X. Tang, J.-Q. Qian, and L.-E. Shi, "Preparation of chitosan nanoparticles as carrier for immobilized enzyme," Applied Biochemistry and Biotechnology, vol. 136, no. 1, pp. 77-96, 2007.

[5] W. Tiyaboonchai, "Chitosan nanoparticles: a promising system for drug delivery," Pharmaceutical Technology, vol. 11, pp. 51-66, 2013.

[6] H. S. Blair, J. Guthrie, T.-K. Law, and P. Turkington, "Chitosan and modified chitosan membranes:preparation and characterization," Journal of Applied Polymer Science, vol. 33, no. 2, pp. 641-656, 1987.

[7] K. M. Varum, M. M. Mhyr, N. J. R. Hjerde, and O. Smidsrod, "In vivo degradation rates of partially $N$-deacetylated chitosans in human serum," Carbohydrate Research, vol. 299, pp. 99-101, 1997.

[8] Y.-L. Hu, W. Qi, F. Han, J.-Z. Shao, and J.-Q. Gao, “Toxicity evaluation of biodegradable chitosan nanoparticles using a zebrafish embryo model," International Journal of Nanomedicine, vol. 6, pp. 3351-3359, 2011.

[9] R. F. Song, X. J. Li, X. L. Cheng et al., "Paclitaxel-loaded trimethyl chitosan-based polymeric nanoparticle for the effective treatment of gastroenteric tumors," Oncology Reports, vol. 32, no. 4, pp. 1481-1488, 2014.

[10] S. Pulavendran, C. Rose, and A. B. Mandal, "Hepatocyte growth factor incorporated chitosan nanoparticles augment the differentiation of stem cell into hepatocytes for the recovery of liver cirrhosis in mice," Journal of Nanobiotechnology, vol. 9, article 15, 2011.

[11] P. Calvo, C. Remuñán-López, J. L. Vila-Jato, and M. J. Alonso, "Novel hydrophilic chitosan-polyethylene oxide nanoparticles as protein carriers," Journal of Applied Polymer Science, vol. 63, no. 1, pp. 125-132, 1997.

[12] K. R. Dobson, L. Reading, M. Haberey, X. Marine, and A. Scutt, "Centrifugal isolation of bone marrow from bone: an improved method for the recovery and quantitation of bone marrow osteoprogenitor cells from rat tibiae and femurae," Journal of Calcified Tissue International, vol. 65, no. 5, pp. 411-413, 1999.

[13] T. Mosmann, "Rapid colorimetric assay for cellular growth and survival: application to proliferation and cytotoxicity assays," Journal of Immunological Methods, vol. 65, no. 1-2, pp. 55-63, 1983.

[14] Q. Gan, T. Wang, C. Cochrane, and P. McCarron, "Modulation of surface charge, particle size and morphological properties of chitosan-TPP nanoparticles intended for gene delivery," Colloids and Surfaces B: Biointerfaces, vol. 44, no. 2-3, pp. 6573, 2005.

[15] K. Haliza and A. H. Oya, "Development and characterization of chitosan nanoparticles for siRNA delivery," Journal of Controlled Release, vol. 115, pp. 216-225, 2006.

[16] Q. Gan, T. Wang, C. Cochrane, and P. McCarron, "Modulation of surface charge, particle size and morphological properties of chitosan-TPP nanoparticles intended for gene delivery," Colloids and Surfaces B: Biointerfaces, vol. 44, no. 2-3, pp. 65-73, 2005.

[17] P. Opanasopit, P. Aumklad, J. Kowapradit et al., "Effect of salt forms and molecular weight of chitosans on in vitro permeability enhancement in intestinal epithelial cells (Caco2)," Pharmaceutical Development and Technology, vol. 12, no. 5, pp. 447-455, 2007.

[18] S. C. W. Richardson, H. V. J. Kolbe, and R. Duncan, "Potential of low molecular mass chitosan as a DNA delivery system: biocompatibility, body distribution and ability to complex and protect DNA," International Journal of Pharmaceutics, vol. 178, no. 2, pp. 231-243, 1999.

[19] Y. Yang, Q. He, L. Duan, Y. Cui, and J. Li, "Assembled alginate/chitosan nanotubes for biological application," Biomaterials, vol. 28, no. 20, pp. 3083-3090, 2007. 

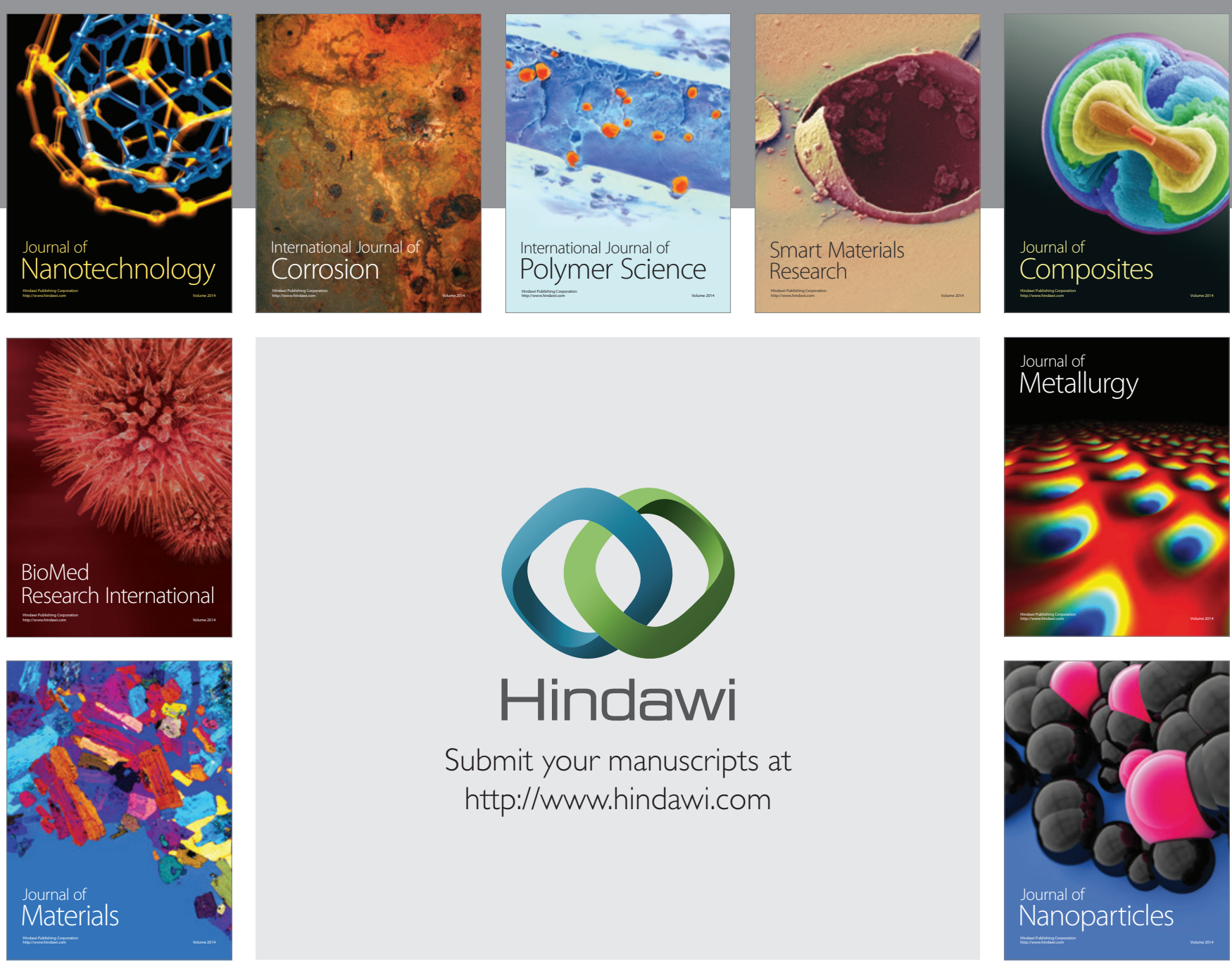

Submit your manuscripts at http://www.hindawi.com
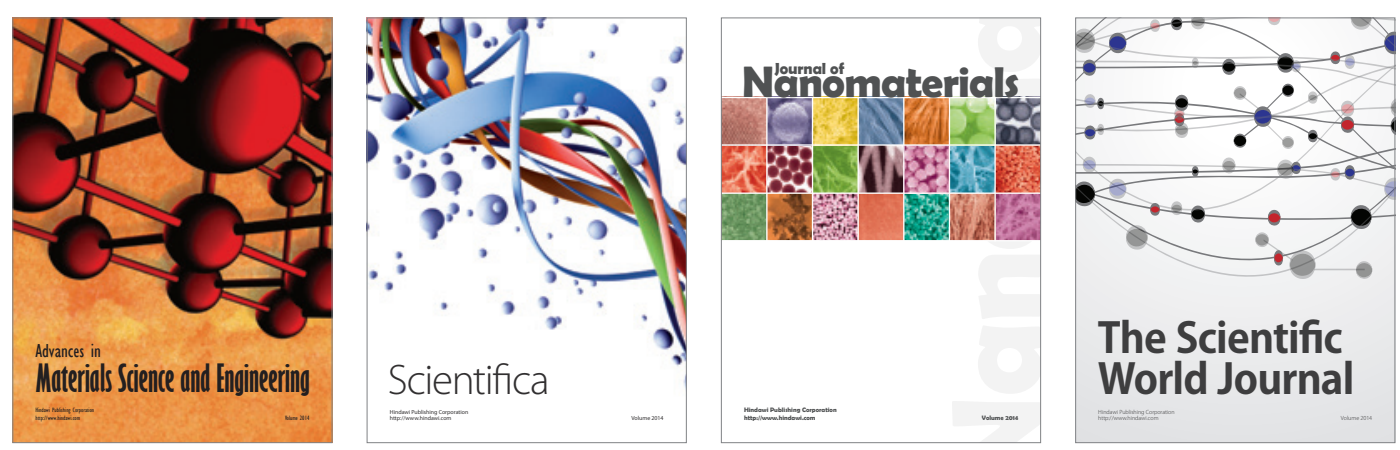

\section{The Scientific World Journal}
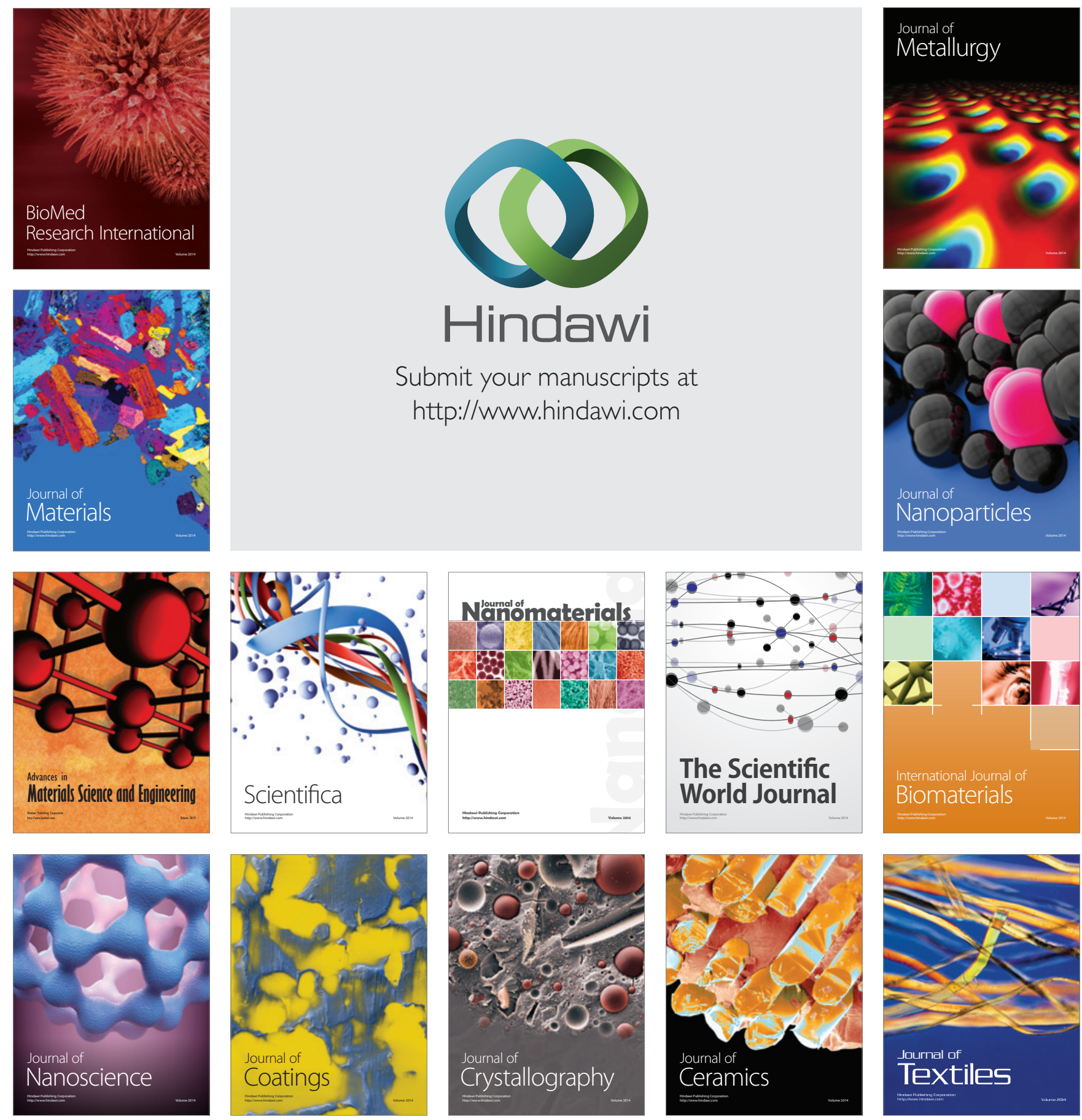